Journal of

Molecular Microbiology

and Biotechnology
J Mol Microbiol Biotechnol 2007;12:263-268

DOI: $10.1159 / 000099647$

\title{
In vitro Interconversion of the Soluble and Membrane- Integrated Forms of the Escherichia coli Glucose Enzyme II of the Phosphoenolpyruvate-Dependent Sugar-Transporting Phosphotransferase System
}

\author{
Mohammad Aboulwafa ${ }^{1}$ Milton H. Saier, Jr. \\ Division of Biological Sciences, University of California at San Diego, La Jolla, Calif., USA
}

\section{Key Words}

Sugar permeases · Escherichia coli • Phosphoenolpyruvatedependent phosphotransferase system • Integral membrane permeases $\cdot$ Solubilization

\begin{abstract}
In previous publications, we have shown that integral membrane sugar permeases of the bacterial phosphotransferase system can exist in a 'soluble' (probably micellar) monomeric form (SII) as well as a membrane-integrated dimeric form (MII). We here show that the two forms of the his-tagged glucose permease of Escherichia coli can be interconverted in vitro. Conversion of MII to SII is promoted by (1) low protein concentration, (2) detergent, (3) high $\mathrm{pH}$, and (4) phospholipase $A_{2}$ treatment. Conversion of SII to $\mathrm{MII}$ is promoted by: (1) high protein concentration, (2) adherence to and elution from an $\mathrm{Ni}^{2+}$ column, (3) neutral $\mathrm{pH}$, and (4) incorporation into phospholipid liposomes.
\end{abstract}

Copyright $\odot 2007$ S. Karger AG, Basel

\footnotetext{
Permanent address: Department of Microbiology and Immunology, Faculty of Pharmacy, Ain Shams University, Cairo, Egypt.
}

\section{Introduction}

In previous publications, we have shown that membrane-integrated permeases (enzymes II) of the bacterial phosphoenolpyruvate-dependent phosphotransferase (PTS) can exist in soluble, cytoplasmic, possibly micellar forms both in vivo and in vitro [Aboulwafa and Saier, $2003,2004]$. The soluble form (SII) appears to be the monomeric protein while the membrane-integrated form (MII) is oligomeric [Aboulwafa and Saier, 2003, 2004; Broos et al., 1998; Erni, 1986; Koning et al., 1999; Leonard and Saier, 1981; Meins et al., 1988; van Montfort et al., 2001, 2002]. These sugar permease enzymes have been shown to catalyze two chemical reactions, both of which can occur in a vectorial fashion:

(1) Sugar (out) + PEP (in) $\stackrel{\substack{\text { EI, HPr } \\ \text { IIABC }}}{\longrightarrow}$ Sugar-P (in) + Pyruvate (in)

$(2)$ * Sugar (out) + Sugar-P (in) $\stackrel{\text { IIBC }}{\rightleftharpoons}{ }^{*}$ Sugar-P (in) + Sugar (out)

The second reaction shown is called the transphosphorylation (TP) reaction and is catalyzed by all PTS enzymes II [Saier et al., 1977a-c]. The TP reaction for the glucose enzyme II ( $\mathrm{II}^{\mathrm{Glc}}$ ) of Escherichia coli has been shown to exhibit differing kinetic properties, depending on whether $\mathrm{II}^{\mathrm{Glc}}$ is in the SII or MII form [Aboulwafa and Saier, 2004]. Specifically, SII does not exhibit substrate (sugar-P) inhibition when the concentration of the radioactive sugar is maintained constant and that of the sugar-P is increased,

\section{KARGER}

Fax +4161306 1234

E-Mail karger@karger.ch

www.karger.com
(C) 2007 S. Karger AG, Basel

Accessible online at: www.karger.com $/ \mathrm{mmb}$
Milton $\mathrm{H}$ Saier Jr.

Division of Biological Sciences

University of California at San Diego

La Jolla, CA 92093-0116 (USA)

Tel. +1 858534 4084, Fax +1 858534 7108,E-Mail msaier@ucsd.edu 

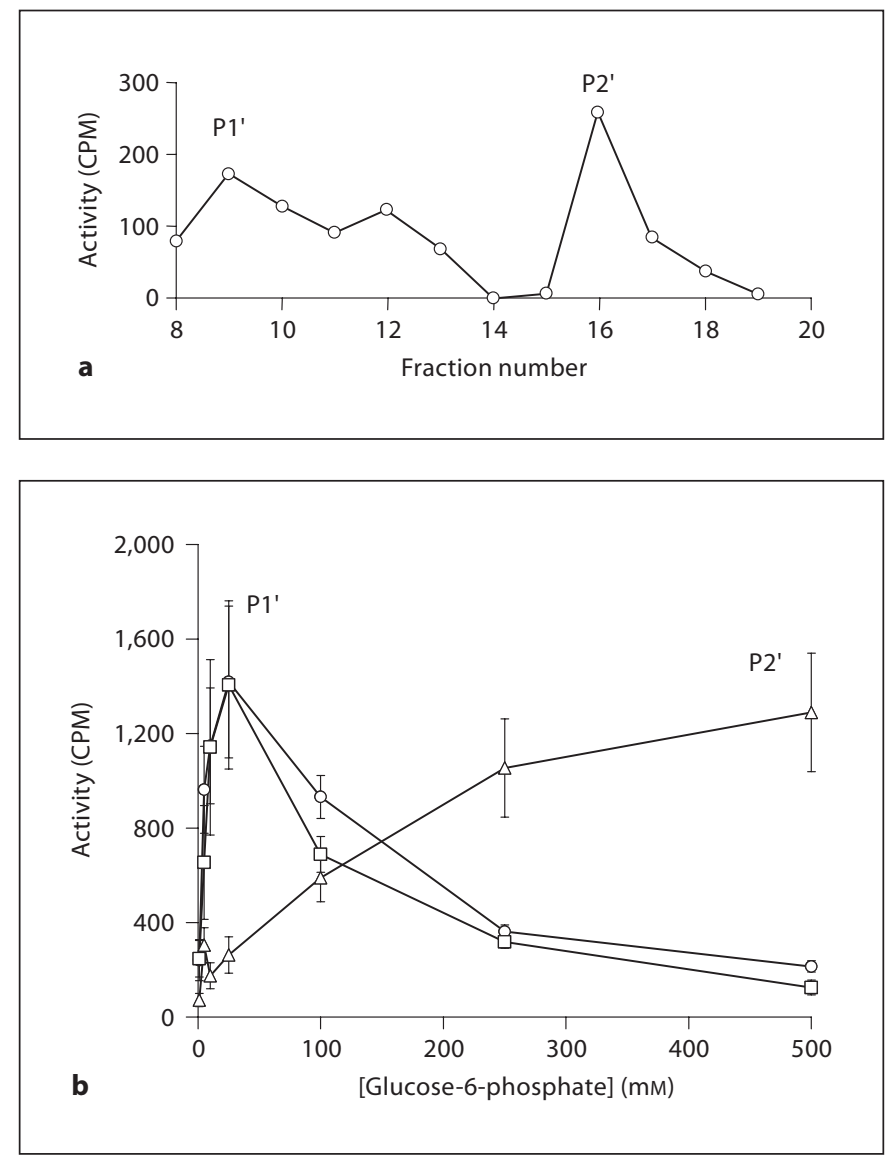

Fig. 1. Conversion of SII to MII by passage through an $\mathrm{Ni}^{2+}$ column followed by concentration. a Gel filtration of $\mathrm{Ni}^{2+}$ columnpurified and concentrated N-his II Glc SII (peak 2). After an HSS was passed through a Biogel filtration column, P2 (SII) was purified on an $\mathrm{Ni}^{2+}$ column and concentrated using an Amicon Ultra 30,000 MWCO filter before it was again passed through the gel filtration column. The elution profile reveals conversion of some of SII (P2) to MII (P1) following purification on the $\mathrm{Ni}^{2+}$ column and concentration. This experiment was repeated several times, and although conversion to MII (P1) was always observed, variability in the amount of conversion (30-60\%) was observed. b TP activity of fractions $9(\square), 12(\bigcirc)$ and $16(\triangle)$ from the elution profile shown in a as a function of glucose-6-phosphate concentration, assayed under standard conditions [Aboulwafa and Saier, 2004]. While fractions 9 and 12 exhibit substrate inhibition (characteristic of MII), fraction 16 does not (characteristic of SII).

but MII does [Aboulwafa and Saier, 2004]. This fact provides a convenient assay for the interconversion of these two forms of the enzyme. We therefore used this assay as well as gel filtration to study the his-tagged form of $\mathrm{II}^{\mathrm{Glc}}$, and showed that the two forms can be interconverted in vitro. The conditions promoting the formation of each of these two forms were defined as reported here.

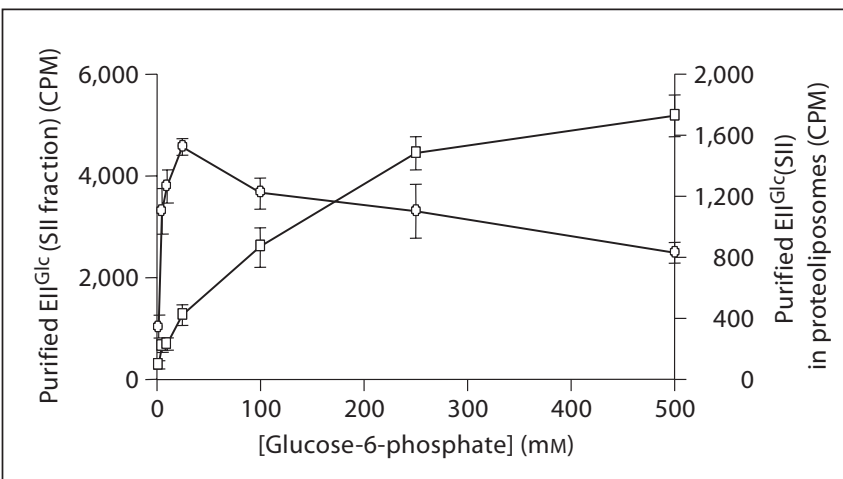

Fig. 2. Effect of liposome association of SII on the catalytic behavior of II ${ }^{\text {Glc }}$ in the TP reaction. Purified SII (P2) N-his II Glc was assayed for the TP reaction as a function of glucose-6-phosphate concentration $(\square)$. Subsequently, it was incorporated into preformed liposomes and assayed again $(\bigcirc)$.

\section{Results}

Conversion of the Soluble Enzyme II (Gel Filtration Peak 2; P2; SII) into the Membrane-Associated

Enzyme II (Gel Filtration Peak 1; P1; MII)

E. coli strain BL21GH4 bearing the plasmid encoding the N-terminally his-tagged $\mathrm{II}^{\mathrm{Glc}}\left(\mathrm{N}\right.$-his-II $\left.{ }^{\mathrm{Glc}}\right)$ was grown, and the 2-hour high-speed supernatant (HSS) was prepared as described under 'Experimental Procedures'. The 2-hour HSS was passed through a Biogel (Biogel A-1.5 m fine-grade, exclusion limit $<10,000-1,500,000$, Bio-Rad) filtration column at $4^{\circ} \mathrm{C}$ yielding two peaks when assayed by the TP assay, peak 1 (P1; MII) and peak 2 (P2; SII), as described previously [Aboulwafa and Saier, 2003]. While peak 1 showed strong substrate inhibition, peak 2 showed none as reported previously. P2 his-II ${ }^{\mathrm{Glc}}$ (SII) was purified on a pre-equilibrated (his-tagged protein-binding buffer containing imidazole) $\mathrm{Ni}^{2+}$ column. The histagged $\mathrm{II}^{\mathrm{Glc}}$ was washed and eluted as described by Aboulwafa and Saier [2004]. It was then assayed using the TP reaction as a function of glucose-6-phosphate concentration. Mild substrate inhibition was observed [see Aboulwafa and Saier, 2004]. The eluate was concentrated (with an Amicon Ultra 30,000 MWCO filter). The concentrated $\mathrm{Ni}^{2+}$ column-purified SII (P2) was again applied to a Biogel filtration column, and two peaks of activity, $\mathrm{P} 1^{\prime}$ (MII) and P2' (SII), were eluted in medium 63 (M63) at $\mathrm{pH}$ 7.0. Different relative amounts of $\mathrm{P}^{\prime}$ and $\mathrm{P} 2^{\prime}$ activity were obtained in different preparations, but the two peaks were fairly comparable in magnitude, with between 30 and $60 \%$ of the activity in $\mathrm{P}^{\prime}$ (see, for example, fig. 1a). 
$\mathrm{P1}^{\prime}$ (fractions 9-12) showed substrate inhibition in the TP reaction, but $\mathrm{P}^{\prime}$ (fraction 16) did not (fig. 1b). It was therefore concluded that partial conversion of SII (P2; monomeric) into MII (P1; oligomeric) had occurred.

$\mathrm{Ni}^{2+}$ column-purified his-II ${ }^{\mathrm{Glc}}$ from $\mathrm{P} 2$ was passed through the Biogel filtration column, and P2' (SII) was assayed (TP reaction) as a function of glucose-6-phosphate concentration. Virtually no substrate inhibition was observed (fig. 2). This enzyme was incorporated into liposomes as described in the legend to figure 2 . The results of the TP assay are shown in figure 2. Although the starting material showed practically no substrate inhibition in the TP reaction, the liposome-associated enzyme exhibited very substantial substrate inhibition. These results suggest that lipid bilayer association tends to convert SII to MII with the expected change in catalytic properties.

\section{Conversion of MII (P1) into Soluble SII (P2) and Back Again}

E. coli strain BL21GH4 bearing the plasmid encoding the $\mathrm{N}$-terminally his-tagged $\mathrm{II}^{\mathrm{Glc}}\left(\mathrm{N}\right.$-his-II $\left.{ }^{\mathrm{Glc}}\right)$ was grown as described under 'Experimental Procedures', and the pellet fraction was separated by high-speed centrifugation. When the pellet fraction was passed through the Biogel filtration column [Aboulwafa and Saier, 2003], only P1 (not P2) was observed. This pellet fraction was brought to $\mathrm{pH} 8.9$ in M63 buffer, and the enzyme was solubilized with $2 \%$ Triton X100 (with stirring at $4^{\circ} \mathrm{C}$ for $7.5 \mathrm{~h}$ ) [Aboulwafa and Saier, 2004]. The extract was passed through a $0.45-\mu \mathrm{m}$ Millipore filter, and 1 or $2.5 \mathrm{ml}$ of the protein solution was loaded onto a Biogel filtration column as described previously [Aboulwafa and Saier, 2003]. The enzyme was eluted with M63 containing $0.1 \%$ Triton $\mathrm{X} 100$ at $\mathrm{pH}$ 8.9. A large peak 1 (P1; MII) was observed as well as a small peak 2 (P2; SII) (fig. 3a). P2 exhibited no substrate inhibition, although P1 did (fig. 3b). These experiments show that detergent treatment at high $\mathrm{pH}$ converts some of the membrane-integrated oligomeric MII into the soluble, monomeric SII.

P2 (SII) from the above experiment was collected and concentrated using an Amicon Ultra 30,000 MWCO filter. An aliquot of $2.5 \mathrm{ml}$ of the concentrate produced was loaded onto a Biogel filtration column and eluted under the same conditions described above using the same eluant. Two peaks, a large peak 1 and a smaller peak 2, were produced (fig. 4). Once again, the large peak 1 showed substrate inhibition but the small peak 2 did not (data not shown). His-tagged EII ${ }^{\mathrm{Glc}}$ from the solubilized pellet was purified with an $\mathrm{Ni}^{+}$column using standard procedures. Purified his-tagged EII Glc from P2 of the concentrated
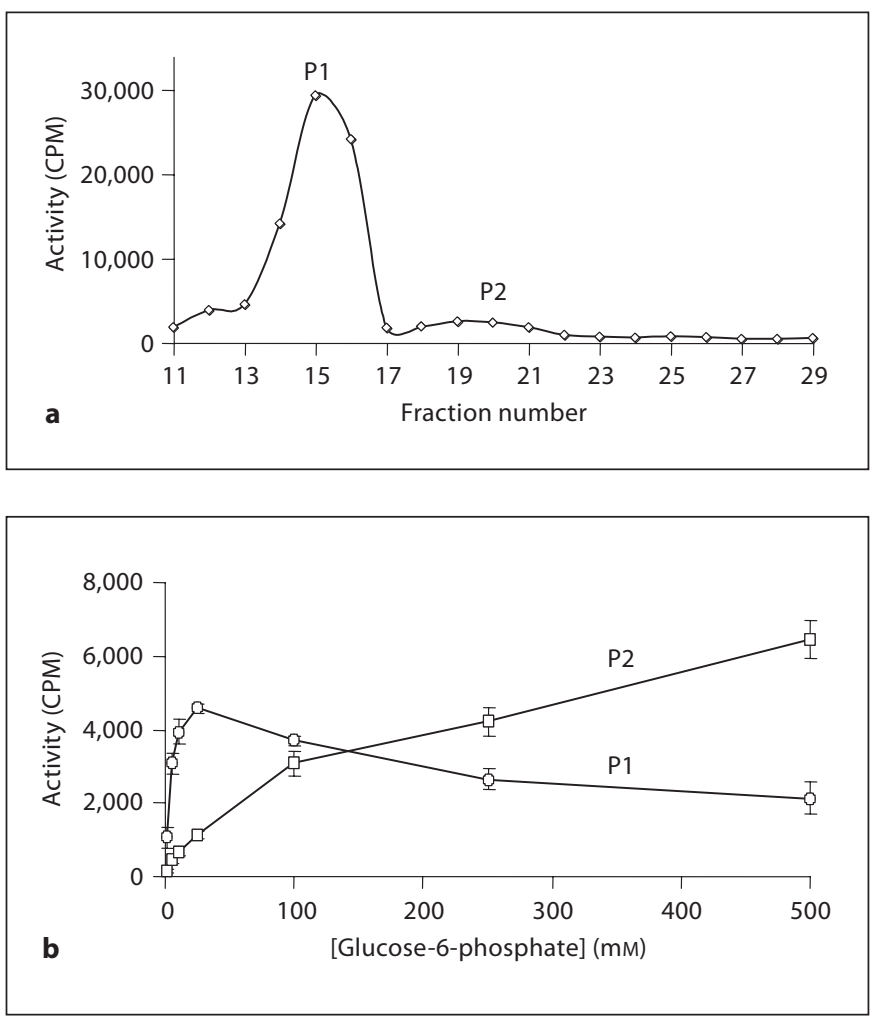

Fig. 3. Effect of detergent treatment on the kinetic properties of II $^{\text {Glc }}$. a Gel filtration profile of $2 \%$ Triton X100-solubilized pellet (incubated for $7.5 \mathrm{~h}$ in $\mathrm{M} 63$ buffer, $\mathrm{pH} 8.9$ at $4^{\circ} \mathrm{C}$ ). b TP assay of the two peaks from the gel filtration column (a) as a function of glucose-6-phosphate concentration at a constant $(50 \mu \mathrm{M})$ concentration of $\left[{ }^{14} \mathrm{C}\right]$ methyl $\alpha$-glucoside. The amounts of protein in the reaction mixtures were 8.5 and $90 \mu \mathrm{g}$ for $\mathrm{P} 1$ and $\mathrm{P} 2$, respectively. Peak 1 (P1; MII; O) shows substrate inhibition, while peak 2 (P2; SII; $\square)$ does not.

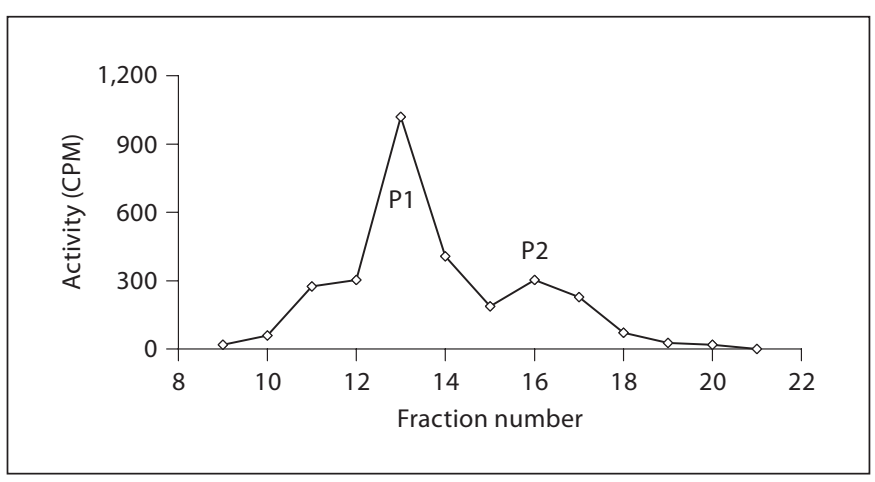

Fig. 4. Gel filtration of $2.5 \mathrm{ml}$ of concentrated (with an Amicon Ultra 30,000 MWCO filter) P2 (SII) derived from the Triton X100-solubilized pellet of BL21GH4 (gel filtration peak 2). The column was eluted with M63 at pH 8.9 in the presence of $0.1 \%$ Triton X100. 


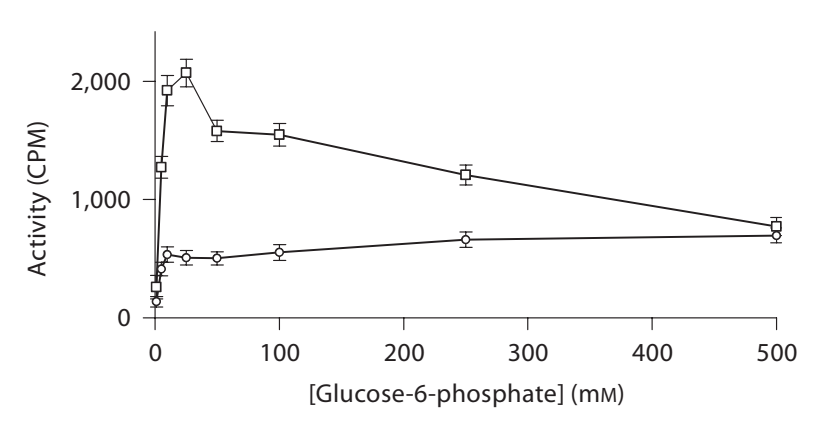

Fig. 5. Effects of PLA2 treatment on TP activities of Ni columnpurified EII ${ }^{\mathrm{Glc}}$. Peak 2 of solubilized pellet from E. coli strain BL21GH4 was passed through the Ni column, concentrated, and passed through the gel filtration column again to yield P1 (MII). PLA2 from porcine pancreas (1,500 units) (Sigma catalogue No. PO861) was incubated for $60 \mathrm{~min}$ at $\mathrm{pH} 8$ and $40^{\circ} \mathrm{C}$ with $3.75 \mu \mathrm{g}$ of this preparation, with mild shaking. The figure shows the TP reaction as a function of glucose-6-phosphate concentration before $(\square)$ and after $(\bigcirc)$ PLA2 treatment.

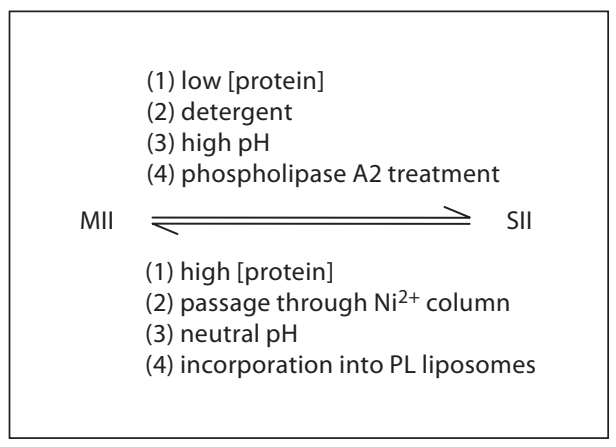

Fig. 6. Summary of conditions that promote the reversible interconversion of the membrane-integrated form of $\mathrm{II}^{\mathrm{Glc}}$ (MII) and the soluble form (SII).

detergent-solubilized pellet was twice dialyzed $(5 \mathrm{ml}$ against 21 M63 plus 2 mM DTT, pH 7, over a 24 -hour period). This enzyme was assayed for TP activity both before and after dialysis at different concentrations of glucose-6-phosphate and $50 \mu \mathrm{M}\left[{ }^{14} \mathrm{C}\right]$ methyl $\alpha$-glucoside. Mild substrate inhibition was observed before dialysis, and stronger inhibition was observed after dialysis (data not shown), although the starting material (peak 2 from the solubilized pellet) had shown no substrate inhibition.

An aliquot of the Ni column-purified and dialyzed his-tagged EII ${ }^{\mathrm{Glc}}$, obtained from P2 of the solubilized pellet, was concentrated and loaded onto a Biogel filtration column and eluted at neutral $\mathrm{pH}$ with M63. A peak 1, but no peak 2, was observed (see fig. S1A on our website; http://www.biology.ucsd.edu/ msaier/supmat/MIISII). The TP activities of the different fractions representing peak 1 at different concentrations of glucose-6-phosphate and $50 \mu \mathrm{M}\left[{ }^{14} \mathrm{C}\right]$ methyl- $\alpha$-glucoside are shown in figure S1B (http://www.biology.ucsd.edu/ msaier/supmat/MII-SII). The results show that purification and elution from an $\mathrm{Ni}^{+}$column followed by concentration and dialysis promoted the conversion of SII, obtained from the solubilized pellet, to MII.

The above-described experiments show that both $\mathrm{Ni}^{2+}$ column purification and protein concentration/dialysis convert the purified monomeric form of $\mathrm{II}^{\mathrm{Glc}}$ (SII) to a form exhibiting the properties of the oligomeric form (MII). However, both forms of the enzyme must subsequently be relatively stable, allowing their separation by gel filtration and assay using the TP reaction. Conversion of SII (P2) to MII (P1) therefore occurs slowly and is promoted by both purification on the $\mathrm{Ni}^{2+}$ column and concentration of the protein.

\section{Conversion of MII to SII by Treatment with Phospholipase $\mathrm{A}_{2}$}

As shown in figure 5, when the purified P1 (MII), obtained following $\mathrm{Ni}^{2+}$ column purification and concentration, was assayed for substrate inhibition in the TP reaction, both before and after phospholipase $\mathrm{A}_{2}$ (PLA2) treatment, the substrate inhibition observed before PLA2 treatment was largely lost following PLA2 treatment. These observations suggest that purified SII retains phospholipids, that passage through the $\mathrm{Ni}^{2+}$ column followed by concentration promotes formation of the oligomeric MII from the monomeric SII obtained initially from the pellet as noted above, and that exposure to PLA2 partially reverses this process, either converting MII to SII, or causing MII to acquire the catalytic properties of SII. Regardless of the agent or procedure used to affect the equilibrium between SII and MII, both forms can subsequently be separated by gel filtration, and P1 (MII) always shows substrate inhibition while P2 (SII) does not (see also fig. S2 on our website; http://www.biology.ucsd.edu/ $\sim$ msaier/supmat/MII-SII).

\section{Discussion}

The scheme shown in figure 6 summarizes our in vitro findings. Several conditions influence the distribution of $\mathrm{II}^{\mathrm{Glc}}$ between the MII (oligomeric; probably dimeric) 
form and the SII (monomeric) form. These include (1) protein concentration, (2) detergent, (3) $\mathrm{pH},(4)$ passage through an $\mathrm{Ni}^{2+}$ column, and (5) the availability of phospholipids in bilayer form. How each of these conditions or agents influences the relative proportions of MII and SII is fully consistent with our bilayer (MII) $\leftrightarrow$ micelle (SII) proposal [Aboulwafa and Saier, 2004]. After PLA treatment, it is possible that the lysophospholipids and/or detergent molecules present participate in micelle formation. These results are in general agreement with our previous results [Aboulwafa and Saier, 2003, 2004] as well as those of Broos et al. [1998].

In summary, we have demonstrated that the 'soluble' and 'membrane-integrated' forms of the enzyme II Glc (SII and MII, respectively) can be interconverted in vitro. The conditions that favor formation of one or the other of these two forms have been defined (fig. 6). Definition of these in vitro conditions are likely to lead to an understanding of the conditions that maintain the distribution of these two forms in vivo [Aboulwafa and Saier, 2003, 2004]. Such an understanding will hopefully lead to the in vivo manipulation and consequent appreciation of the physiological significance, if any, of the cytoplasmic forms of PTS enzymes II.

\section{Experimental Procedures}

The methods and the commercially obtained compounds used have been described in our earlier publications [Aboulwafa and Saier, 2003, 2004] or are presented here and in the figure legends. Strain BL21GH4 bears a plasmid encoding the N-terminally his-tagged $\mathrm{II}^{\mathrm{Glc}}$ (N-his-II ${ }^{\mathrm{Glc}}$ ) and was made by Dr. Ming Ren Yen. All of the work reported in this paper was performed with this N-his-tagged enzyme.

Bacterial Growth and Crude Enzyme Preparation

Strain BL21GH4 (pET19b- $\mathrm{H}_{4}-p t s G a m p^{\mathrm{r}}$ ) was grown in $2 \times$ TY medium (tryptone, 12 g; yeast extract, 24 g; water, 1 l; 250 $\mathrm{rpm})$. Ampicillin was added to a final concentration of $100 \mu \mathrm{g} /$ $\mathrm{ml}$, and cells were grown to an OD of 0.8 absorbency units. Then isopropyl- $\beta-D$-thiogalactopyranoside was added to the final concentration of $0.2 \mathrm{mM}$, and incubation was continued for $24 \mathrm{~h}$ at $37^{\circ}$ with shaking $(250 \mathrm{rpm})$ before harvesting. Cells were washed $3 \times$ with M63 and resuspended in $35 \mathrm{ml}$ of the same medium. These suspensions were passed through a French press $3 \times$ at $0^{\circ} \mathrm{C}$ and 16,000 psi. The cell lysate was centrifuged at $10,000 \mathrm{rpm}$ in a Sorvall ${ }^{\circledR} \mathrm{SS}-34$ rotor at $4^{\circ} \mathrm{C}$ for $10 \mathrm{~min}$. The supernatants represent the crude extracts which were centrifuged at $40,000 \mathrm{rpm}(100,000 \mathrm{~g})$ for $2 \mathrm{~h}$ in a Beckman Ti50 rotor to give the pellet and the HSS. The pellet was suspended in $10 \mathrm{ml}$ of M63.

Liposome formation and $\mathrm{II}^{\mathrm{Glc}}$ incorporation were accomplished as follows: Commercial phosphatidylglycerol (PG, $5 \mathrm{mg}$ ) plus purified E. coli phosphatidylethanolamine (PE, $15 \mathrm{mg}$ ) both from Sigma in $2 \mathrm{ml}$ of M63/5 mM DTT was vortexed, and an aliquot of $0.5 \mathrm{ml}$ in a $15 \times 1.6 \mathrm{~cm}$ (internal diameter) Pyrex tube was flushed with $\mathrm{N}_{2}$ gas. The tube was sealed, and the suspension was sonicated intermittently for a total of $80 \mathrm{~min}$ in an ice bath using a bath sonicator (G11 SP1 special ultrasonic cleaner, Laboratory Supplies, Inc., Hicksville, N.Y., USA). The temperature did not exceed $8^{\circ} \mathrm{C}$. Reconstitution was achieved without further sonication using the detergent dilution procedure as described previously [Ambudkar and Maloney, 1986; Leonard and Saier, 1983]. An aliquot (SII; P2) of $0.5 \mathrm{ml}$ (965 $\mu \mathrm{g}$ protein), obtained by gel filtration of dialyzed $\mathrm{Ni}^{2+}$ column-purified $\mathrm{N}$-his EII Glc , was added to the liposomes and mixed; $50 \mu \mathrm{l}$ of $2 \%$ Triton $\mathrm{X} 100$ was then added to give a final Triton concentration of $0.1 \%$. This mixture was kept on ice for $45 \mathrm{~min}$. It was then diluted 30 fold by pipetting into $\mathrm{M} 63 / 5 \mathrm{mM}$ DTT, vortexed and centrifuged at $45,000 \mathrm{rpm}$ (Ti50 rotor) for $1 \mathrm{~h}$. The supernatant produced was discarded, and the sedimented proteoliposomes were resuspended in $1 \mathrm{ml}$ of M63/5 mM DTT and immediately used for assay. The TP reaction was assayed as described previously [Aboulwafa and Saier, 2003, 2004] using $50 \mu \mathrm{M}\left[{ }^{14} \mathrm{C}\right]$ methyl $\alpha$-glucoside and variable concentrations of glucose-6-P. The amount of protein in the reaction mixture was $96 \mu \mathrm{g}$, both with and without liposomes.

The effect of PLA2 treatment was measured as follows. The pellet fraction or $\mathrm{Ni}^{2+}$ column-purified EII ${ }^{\mathrm{Glc}}$ was incubated with 1,500 units of PLA2 per ml (PLA2 from porcine pancreas; Sigma catalogue No. PO861) [1 unit of enzyme produces $1 \mu \mathrm{mol}$ of free fatty acid per min at $\mathrm{pH} 8$ and at $40^{\circ} \mathrm{C}$ using lecithin phosphatidylcholine $(\mathrm{PC})$ as the substrate. It preferentially hydrolyzes the $\beta$-ester bonds of zwitterionic glycerophospholipids (PC and PE), but anionic lipids, PG, phosphatidylinositol (PI) and phosphatidylserine (PS), are also hydrolyzed. The enzyme attacks phospholipids in the membranes of intact cells]. Incubation was for 60 min at $40^{\circ} \mathrm{C}$ with mild shaking. The preparations before and after PLA2 treatment were either assayed directly $\left(\mathrm{Ni}^{2+}\right.$ column-purified EII ${ }^{\text {Glc}}$; fig. 5) or the treated preparation (for the pellet fraction) was applied to the gel filtration column, and the two peaks of activity (fig. S2A on our website; http://www.biology.ucsd.edu/ $\sim$ msaier/supmat/MII-SII) were assayed for the TP reaction as a function of glucose-6-phosphate concentration (fig. S2B on our website; http://www.biology.ucsd.edu/ msaier/supmat/MII-SII) using standard assay conditions [Aboulwafa and Saier, 2003, 2004]. The assay incubation time was $1 \mathrm{~h}$. The results show that some of the pellet fraction (MII) acquired the properties of the soluble enzyme (SII).

\section{Acknowledgments}

We thank Dr. M.R. Yen for constructing the N-his-tagged $\mathrm{II}^{\mathrm{Glc}}$-encoding plasmid, pET19b- $\mathrm{H}_{4}-\mathrm{pts} \mathrm{G} a m p^{\mathrm{r}}$. This work was supported by NIH grant GM64368. We thank Mary Beth Hiller for her assistance in the preparation of this paper. 


\section{References}

Aboulwafa M, Saier MH Jr: Soluble sugar permeases of the phosphotransferase system in Escherichia coli: Evidence for two physically distinct forms of the proteins in vivo. Mol Microbiol 2003;48:131-141.

- Aboulwafa M, Saier MH Jr: Characterization of soluble enzyme II complexes of the Escherichia coli phosphotransferase system. J Bacteriol 2004;186:8453-8462.

-Ambudkar SV, Maloney PC: Bacterial anion exchange. Use of osmolytes during solubilization and reconstitution of phosphate-linked antiport from Streptococcus lactis. J Biol Chem 1986;261:10079-10086.

Broos J, Hoeve-Duurkens RT, Robillard GT: A mechanism to alter reversibly the oligomeric state of a membrane-bound protein demonstrated with Escherichia coli $\mathrm{EII}^{\mathrm{mtl}}$ in solution. J Biol Chem 1998;273:3865-3870.

Erni B: Glucose-specific permease of the bacterial phosphotransferase system: phosphorylation and oligomeric structure of the glucose-specific $\mathrm{II}^{\mathrm{Glc}}$-III ${ }^{\mathrm{Glc}}$ complex of Salmonella typhimurium. Biochemistry 1986;25: 305-312.
Koning RI, Keegstra W, Oostergetel GT, Schuurman-Wolters G, Robillard GT, Brisson A The $5 \AA$ projection structure of the transmembrane domain of the mannitol transporter enzyme II. J Mol Biol 1999;287:845851.

Leonard JE, Saier MH Jr: Genetic dissection of catalytic activities of the Salmonella typhimurium mannitol enzyme II. J Bacteriol 1981;145:1106-1109.

Leonard JE, Saier MH Jr: Mannitol-specific enzyme II of the bacterial phosphotransferase system. II. Reconstitution of vectorial transphosphorylation in phospholipid vesicles. J Biol Chem 1983;258:10757-10760.

- Meins M, Zanolari B, Rosenbusch JP, Erni B: Glucose permease of Escherichia coli. Purification of the $\mathrm{II}^{\mathrm{Glc}}$ subunit and functional characterization of its oligomeric forms. J Biol Chem 1988;263:12986-12993.

- Saier MH Jr, Cox DF, Moczydlowski EG: Sugar phosphate:sugar transphosphorylation coupled to exchange group translocation catalyzed by the enzyme II complexes of the phosphoenolpyruvate:sugar phosphotransferase system in membrane vesicles of Escherichia coli. J Biol Chem 1977c;252:89088916.
Saier MH Jr, Feucht BU, Mora WK: Sugar phosphate:sugar transphosphorylation and exchange group translocation catalyzed by the enzyme II complexes of the bacterial phosphoenolpyruvate:sugar phosphotransferase system. J Biol Chem 1977b;252:8899-8907.

Saier MH Jr, Newman MJ, Rephaeli AW: Properties of a phosphoenolpyruvate:mannitol phosphotransferase system in Spirochaeta aurantia. J Biol Chem 1977a;252:88908898.

van Montfort BA, Schuurman-Wolters GK, Duurkens RH, Mensen R, Poolman B, Robillard GT: Cysteine cross-linking defines part of the dimer and $\mathrm{B} / \mathrm{C}$ domain interface of the Escherichia coli mannitol permease. J Biol Chem 2001;276:12756-12763.

van Montfort BA, Schuurman-Wolters GK, Wind J, Broos J, Robillard GT, Poolman B: Mapping of the dimer interface of the Escherichia coli mannitol permease by cysteine cross-linking. J Biol Chem 2002;277:1471714723. 